\title{
Corrosion Acceleration of Printed Circuit Boards With an Immersion Silver Layer Exposed to Bacillus cereus in an Aerobic Medium
}

\author{
Yuting $\mathrm{Hu}^{\dagger}$, Kui Xiao*t, Dawei Zhang*, Pan Yi, Ruilin Xiong, Chaofang Dong, \\ Jusheng Wu and Xiaogang Li
}

Corrosion and Protection Center, University of Science and Technology Beijing, Beijing, China

OPEN ACCESS

Edited by:

Dake Xu,

Northeastern University, China

Reviewed by:

Hongwei Liu,

Sun Yat-sen University, China

Qing Qu,

Yunnan University, China

*Correspondence:

Kui Xiao

xiaokui@ustb.edu.cn

Dawei Zhang

dzhang@ustb.edu.cn

tThese authors have contributed equally to this work

Specialty section:

This article was submitted to Microbiological Chemistry

and Geomicrobiology,

a section of the journal

Frontiers in Microbiology

Received: 17 February 2019 Accepted: 14 June 2019

Published: 02 July 2019

Citation:

Hu Y, Xiao K, Zhang D, Yi P, Xiong $R$, Dong $C, W U J$ and Li $X$

(2019) Corrosion Acceleration of Printed Circuit Boards With an Immersion Silver Layer Exposed to Bacillus cereus in an Aerobic Medium. Front. Microbiol. 10:1493.

doi: 10.3389/fmicb.2019.01493
In this research, the corrosion behavior of printed circuit boards with an immersion silver layer (PCB-ImAg) exposed to Bacillus cereus bacteria in Luria-Bertani broth was investigated. The growth test demonstrated that $B$. cereus had a high copper tolerance. Analysis of surface and cross-sectional view of the samples after immersion test indicated that metabolites produced by $B$. cereus accelerated the microporous corrosion of PCB-ImAg, and the biofilm that adhered to the surface led to oxygen concentration corrosion. Electrochemical impedance spectroscopy tests confirmed that the microbiologically influenced corrosion of PCB-ImAg was related to the biofilm formation and metabolism.

Keywords: PCB-ImAg, corrosion acceleration, Bacillus cereus, aerobic medium, growth curve, cross-sectional view

\section{INTRODUCTION}

Microorganisms exist widely in the ocean, soil, and many other environmental systems and grow rapidly when conditions are appropriate ( $\mathrm{Gu}$ et al., 2019). The surfaces of metallic materials exposed to these environments may rapidly become colonized with microorganisms, resulting in complicated corrosion problems known as microbiologically influenced corrosion (MIC) (Xu and Gu, 2014; Xu et al., 2016; Li et al., 2018). MIC is estimated to account for $\sim 20 \%$ of all corrosion losses, which amount to over 60 billion US dollars each year in China alone (Flemming, 1996; Hou et al., 2017; Huang et al., 2018).

Bacillus cereus is a species of bacillus that can enter dormancy by forming spores and withstand adverse conditions, such as high temperature, ultraviolet radiation, and lack of nutrients, and is therefore highly tenacious in poor environments (Nakamura and Silver, 1994; Nourbakhsh et al., 2002; Siddiqui et al., 2005; Shivaji et al., 2006). Novikova et al. (2006) surveyed environmental biocontamination on the International Space Station and isolated a large proportion of Bacillus sp. Recently, the impact of this species on materials in various environmental systems has attracted increasing attention. For example, Juzeliūnas et al. (2005) isolated Bacillus mycoides from $\mathrm{Al}, \mathrm{Cu}$, $\mathrm{Zn}$, and steel samples and investigated accelerated MIC in $\mathrm{Zn}$ and inhibition in Al. Qu et al. (2015) reported on the corrosion behavior of cold-rolled steel in artificial seawater containing Bacillus subtilis. The strains formed complete biofilms on the surfaces of the samples, which caused the open circuit potential to continuously decrease, and the $\mathrm{pH}$ of the broth decreased significantly. MIC by Bacillus megaterium has also been found to accelerate the corrosion process of $\mathrm{Al}-\mathrm{Cu}$ alloys 
and damage their mechanical properties (Yousaf et al., 2015). Xu et al. (2013) reported that Bacillus licheniformis grown as nitrate reducing bacteria, caused a $14.5 \mu \mathrm{m}$ maximum pit depth on C1018 carbon steel because nitrate reduction coupled with iron oxidation is thermodynamically favorable. The bacteria formed a biofilm around the inclusions and caused damage through metabolic activity (Jia et al., 2019).

With the development of the economy, printed circuit boards (PCBs) are also becoming increasingly miniaturized and complicated, causing PCBs to become very sensitive to factors such as humidity and pollutants in the environment. Copper is widely used in electronic components and tends to corrode. PCB-Cu gradually forms soluble $\mathrm{CuCl}^{2-}$ in a $\mathrm{Cl}^{-}$-enriched environment, which increases the area of electrolyte layer and accelerates corrosion (Huang et al., 2011). Yi et al. (2016) found that MIC occurred on PCB-Cu exposed in Xishuang Banna. Because there are few pollutants in the local air in Xishuang Banna, the corrosion caused by pollutants and dust is minimal. However, mold spores were found in discolored areas on the samples, and some spores were budding. Immersion silver surface finishing of PCB-Cu is a commonly used method to protect materials from corrosion. Yan et al. (2016, 2017) reported that silver-coated $\mathrm{PCB}-\mathrm{ImAg}$ had strong resistance to $\mathrm{Cl}^{-}$. However, the silver layer is usually thin owing to high cost, which means that there are defects such as micropores on the surface of the layer (Xiao et al., 2017). The copper base and silver layer can form galvanic pairs when PCB-ImAg is exposed to the atmosphere, which causes the copper base to corrode at micropores (Russo et al., 2002). Moreover, silver is sensitive to pollutants containing $\mathrm{S}$, such as $\mathrm{H}_{2} \mathrm{~S}$ and $\mathrm{SO}_{2}$, and dozens of parts per million of these gasses can cause PCB failure; such concentrations are far below the pollution gas limits required for human health. In environments containing $\mathrm{H}_{2} \mathrm{~S}$, the growth rate of $\mathrm{Ag}_{2} \mathrm{~S}$ is linear with respect to time (Zou et al., 2013). Gen et al. (2011) found that in a high-humidity environment, creep corrosion occurred on the surface of samples comprising a copper base with a silver layer, and a large amount of whisker-like copper corrosion products appeared on the surface of the samples due to the presence of the layer. In addition, they found a large amount of microorganisms and corrosion products on the surface of PCBs that had been exposed in a clean atmospheric environment.

The authors have also investigated the influence of microbial colonization on PCBs exposed to natural environments. For example, B. siamensis, B. cereus, and B. subtilis have been isolated on $\mathrm{PCBs}$ exposed to the tropical rainforest climate in Xishuang Banna; the annual average humidity is $81 \%$, the daytime temperature is generally above $30^{\circ} \mathrm{C}$, and the content of $\mathrm{S}$ - and $\mathrm{N}$-containing pollutants is very low. These environmental characteristics provide ideal conditions for the growth of microorganisms. In the present study, the corrosion behavior of a silver-plated copper PCB (PCB-ImAg) was investigated in the presence of $B$. cereus, which was isolated from exposure tests in Xishuang Banna. The exposure tests indicated that silver and copper ions released during the corrosion process of PCBImAg did not completely inhibit microbial growth. The tolerance of $B$. cereus to copper ions and silver ions was confirmed by comparing the growth curves of $B$. cereus in Luria-Bertani (LB) broth with different $\mathrm{CuSO}_{4}$ concentrations. The corrosion behavior of PCB-ImAg immersed in LB broth with and without $B$. cereus was investigated using electrochemical impedance spectroscopy (EIS), and the surface morphology was analyzed using confocal laser scanning microscopy (CLSM), field-emission scanning electron microscopy (FESEM), X-ray photoelectron spectroscopy (XPS), and Raman micro-spectroscopy.

\section{MATERIALS AND METHODS}

\section{Bacteria and Samples}

The strain of $B$. cereus used for this study was isolated from PCB-ImAg after exposure at the Xishuang Banna test station for 3 months. The strain was cultured in LB agar (10 g/L tryptone, $5 \mathrm{~g} / \mathrm{L}$ yeast extract, $10 \mathrm{~g} / \mathrm{L} \mathrm{NaCl}$, and $15 \mathrm{~g} / \mathrm{L}$ agar) at $30^{\circ} \mathrm{C}$.

The samples used in the experiment were purchased from Shenzhen Sprint Circuits Co., Ltd. The thickness of the copper base material was $25 \mu \mathrm{m}$, and that of the silver layer was $0.38 \mu \mathrm{m}$. Prior to testing, the samples were degreased with ethanol before soaking in a $5 \%(\mathrm{v} / \mathrm{v})$ glutaraldehyde solution for $5 \mathrm{~h}$. Subsequently, the samples were transferred to a sterilized $75 \%$ ethanol solution and placed in a sterile operator station. The samples were used within $1 \mathrm{~h}$ after sterilization.

\section{Strain Culturing}

The $B$. cereus strain was inoculated into a $150 \mathrm{~mL}$ Erlenmeyer flask containing $50 \mathrm{~mL}$ sterilized LB broth (10 g/L tryptone, $5 \mathrm{~g} / \mathrm{L}$ yeast extract, and $10 \mathrm{~g} / \mathrm{L} \mathrm{NaCl}$; the broth was autoclaved at $121^{\circ} \mathrm{C}$ for $25 \mathrm{~min}$ ) at $30^{\circ} \mathrm{C}$ on a shaker (BSD-TX370, BOXUN, Shanghai) at a speed of $130 \mathrm{rpm}$ for $24 \mathrm{~h}$ as a bacterial suspension. The cell concentration was determined using optical microscopy (Axio Lab.A1, Zeiss, Germany), and the concentration determined through hemocytometry was $12.9 \times 10^{10} / \mathrm{L}$.

\section{Growth Curve Measurements Copper lon Tolerance of $B$. cereus}

A filtered $(0.22 \mu \mathrm{m})$ solution of copper sulfate $\left(\mathrm{CuSO}_{4}\right)$ was added to the LB broth to concentrations of $0,100,200$, 300 , and $400 \mathrm{mg} / \mathrm{L}$.

\section{Silver Ion Tolerance of $B$. cereus}

A filtered $(0.22 \mu \mathrm{m})$ solution of silver nitrate $\left(\mathrm{AgNO}_{3}\right)$ was added to the broth $(10 \mathrm{~g} / \mathrm{L}$ tryptone, $5 \mathrm{~g} / \mathrm{L}$ yeast extract, and $10 \mathrm{~g} / \mathrm{L} \mathrm{NaNO}_{3}$; the broth was autoclaved at $121^{\circ} \mathrm{C}$ for $25 \mathrm{~min}$ ) to concentrations of 0,25 , and $50 \mathrm{mg} / \mathrm{L}$.

The broth was poured into a 100-well plate, with each well containing $200 \mu \mathrm{L}$ of broth and $2 \mu \mathrm{L}$ of bacteria suspension. Three parallel samples were employed for each concentration. The growth curve at $\mathrm{OD}_{600 \mathrm{~nm}}$ was monitored at $30^{\circ} \mathrm{C}$ for 15 days using an automatic growth curve analyzer (FP-1100-C, Bioscreen, Finland); measurements were collected every $2 \mathrm{~h}$ until the value was stable and then monitored every $12 \mathrm{~h}$ thereafter. 


\section{Immersion Tests}

The samples were inoculated in $150 \mathrm{~mL}$ flasks containing $50 \mathrm{~mL}$ sterilized LB broth with and without bacteria and cultured in an electric incubator (DHP-9052, YIHENG, Shanghai) at $30^{\circ} \mathrm{C}$ for a series of immersion times: 3, 6, and 15 days.

On each sampling day, the samples were removed from the broth with and without bacteria, immersed in PBS buffer for $3 \mathrm{~min}$, placed in $2.5 \%(\mathrm{v} / \mathrm{v})$ glutaraldehyde solution, and stored in the dark at $4^{\circ} \mathrm{C}$ for $12 \mathrm{~h}$. The samples were rinsed with deionized water three times to remove the majority of the glutaraldehyde solution, dehydrated sequentially with 50, 70, 85, and 90 alcohol solutions (14 min each) and then dehydrated three times in 100\% ethanol (15 min each).

\section{Surface Analyses}

The surface morphology of the PCB-ImAg after immersion was determined by CLSM (VK-X250K, Keyence, Japan) and FESEM (QUANTA FEG 250, FEI, United States). The characteristics of the samples after immersion were measured using a focused ion beam (FIB, Zeiss, Germany). XPS (SigmaProbe, ThermoFisher, United States) and Raman micro-spectroscopy (CRS, inVia-Reflex, Renishaw, United Kingdom) were performed to determine the composition of the surface immersed in LB with and without $B$. cereus for 15 days. The XPS was equipped with an $\mathrm{Al} \mathrm{K} \alpha$ monochromator and used a step size of $0.05 \mathrm{eV}$. The Raman spectra of the surface were recorded over $100-2000 \mathrm{~cm}^{-1}$ using laser excitation with a wavelength of $633 \mathrm{~nm}$.

\section{EIS Measurements}

EIS tests were conducted using a potentiostat (Reference 600, Camry Instruments Inc., United States) with a three-electrode system comprising a working electrode, a standard calomel electrode (SCE) as the reference electrode, and a platinum foil as the counter electrode. As the working electrodes, the samples were sealed with silicone rubber to create an exposed area of $1.2 \mathrm{~cm}^{2}$. EIS tests were performed at a stable-state open circuit potential (OCP), and the $\mathrm{AC}$ voltage was $10 \mathrm{mV}$ at frequencies ranging from 0.01 to $10 \mathrm{kHz}$. The tests were conducted in the broth with and without $B$. cereus at $30^{\circ} \mathrm{C}$ for 15 days. The EIS results were fitted and analyzed with ZSimpWin software.

\section{RESULTS}

\section{Bacterial Growth}

Over time, the surfaces of the samples of PCB-ImAg can diffuse copper and silver ions; thus, the tolerance of $B$. cereus to copper and silver ions can be obtained by observing the growth curve of the strain in broths containing the two types of ions.

Figure 1 shows the growth curve of $B$. cereus with silver and copper ions. For the growth curve of $B$. cereus with silver ions (Figure 1A), there were three growth phases for B. cereus in the broth containing $25 \mathrm{mg} / \mathrm{L} \mathrm{AgNO}_{3}$, namely, the adjustment, log, and stationary phases; concentrations of $\mathrm{AgNO}_{3}$ above $50 \mathrm{mg} / \mathrm{L}$ completely inhibited the growth of cells. Compared to the growth curve in the natural broth, the adjustment phase of $B$. cereus in the broth containing $25 \mathrm{mg} / \mathrm{L}_{\mathrm{AgNO}_{3}}$ was extended, and the optical density (OD) values were lower, which means that $B$. cereus has a certain silver ion tolerance: after a certain period of adaptation, the cells can grow and multiply, but toxic silver ions will affect the growth activity of the cells.

For the broth containing copper ions (Figure 1B), there were three growth phases for $B$. cereus in each broth: the lag, log, and stationary phases. In particular, there was no apparent decline until the end of the test because $B$. cereus can form spores to resist adverse conditions. The $B$. cereus in the $\mathrm{CuSO}_{4}$-containing broth exhibited a longer lag period than the B. cereus in the broth without $\mathrm{CuSO}_{4}$ to adapt to the new growing environment. After the log period, toxic metabolites accumulated in the broth, and the available nutrients were reduced, resulting in an imbalance in the number of living and dead cells. Thus, a short fluctuation appeared in the curves, and the bacterial growth entered the stable phase. In the broths with 100 and $200 \mathrm{mg} / \mathrm{L} \mathrm{CuSO}_{4}$, the OD values of the bacterial suspension were almost the same as that of the control broth. However, in the broths with 300 and $400 \mathrm{mg} / \mathrm{L}$ $\mathrm{CuSO}_{4}$, the values were significantly lower. The adjustment period of bacterial growth became longer with increasing $\mathrm{CuSO}_{4}$
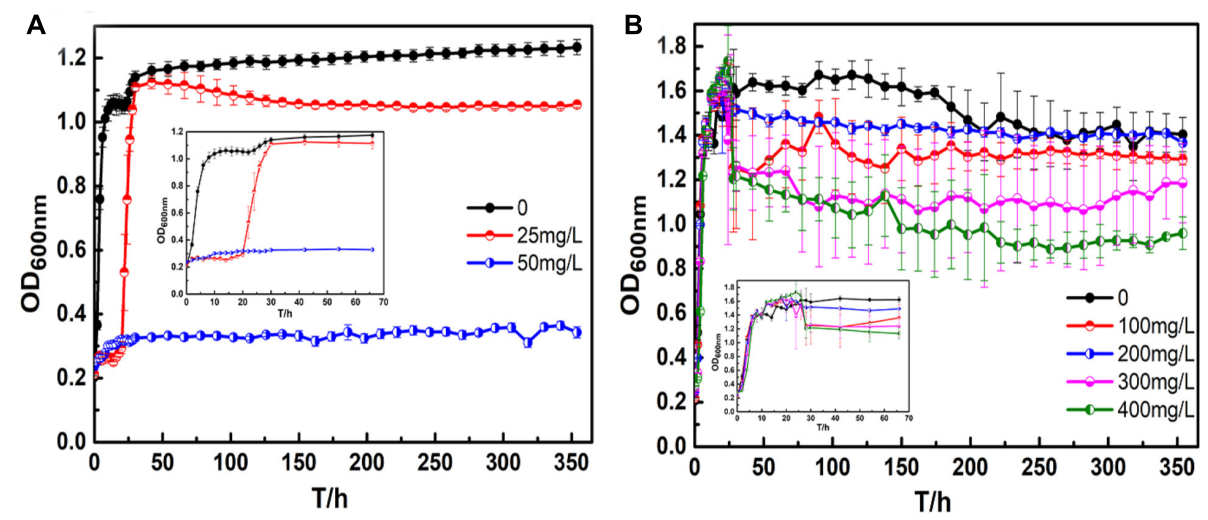

FIGURE 1 | Bacillus cereus growth curves: (A) silver ions, and (B) copper ions. 


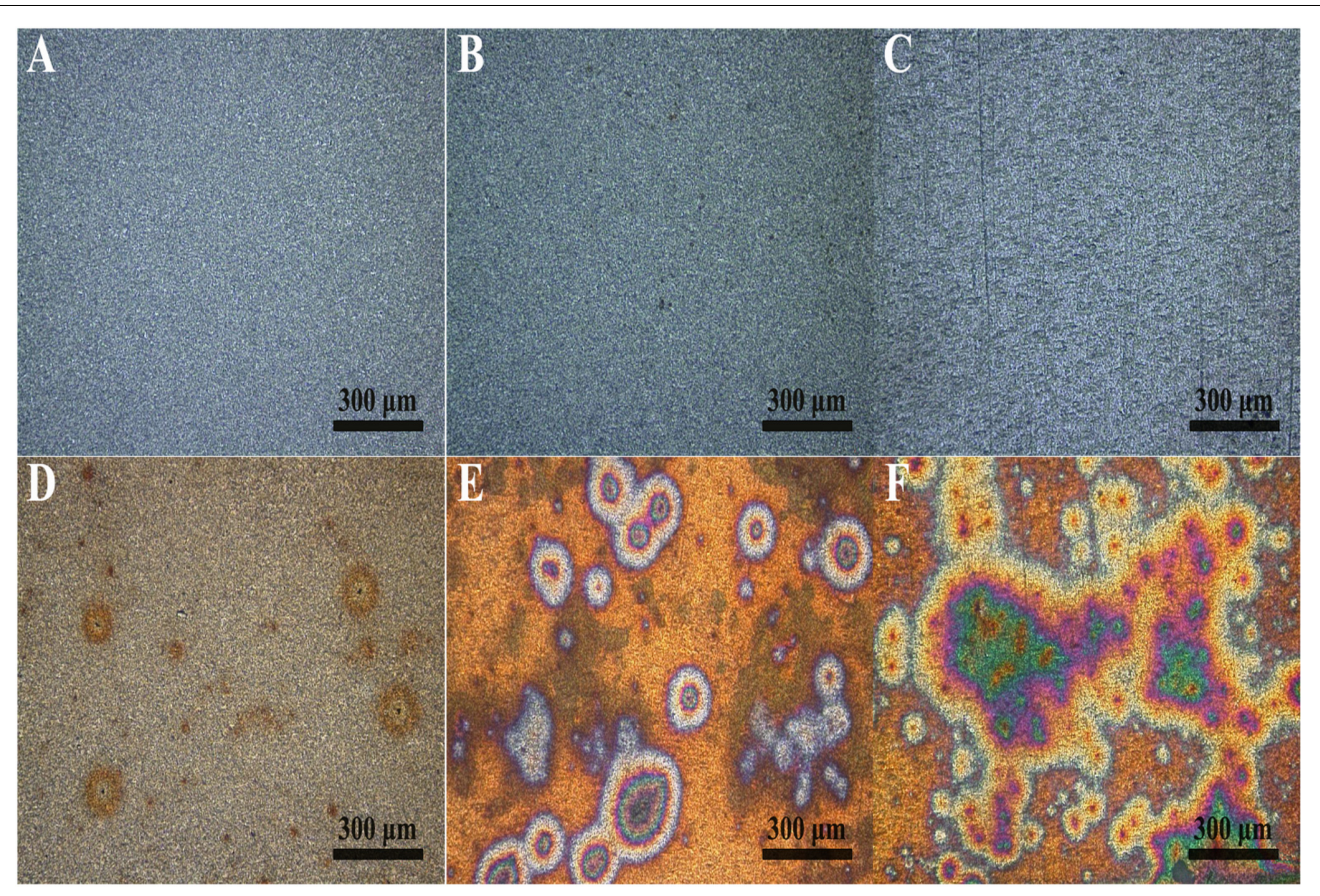

FIGURE 2 | Macroscopic morphology determined using CLSM on the sample surface: (A-C) immersed in the broth without B. cereus for 3, 6, and 15 days and (D-F) immersed in the broth with $B$. cereus for 3, 6, and 15 days.

concentration, and the time to reach the stationary phase also increased. In the stationary phase, the OD values of the broths containing 100 and $200 \mathrm{mg} / \mathrm{L} \mathrm{CuSO}_{4}$ were almost the same, whereas the values of the broths containing 300 and $400 \mathrm{mg} / \mathrm{L}$ $\mathrm{CuSO}_{4}$ were significantly lower.

\section{Surface Analysis}

Figure 2 shows the macroscopic morphology of PCB-ImAg samples immersed in LB broth with and without B. cereus for 3, 6, and 15 days. In the sterile medium, the sample surface showed a slight color variation during the 15 days of immersion. However, the silver layer was intact. In comparison, the surface morphology of the samples immersed in the inoculated broth exhibited a rapid and significant change within the 15 days of culture. After 3 days of immersion (Figure 2D), although some corrosion spots could be observed on the PCB-ImAg surface, the color of the original silver layer was relatively clearly visible. Figure $2 \mathbf{B}$ shows that after 6 days, most of the surface of the sample showed a considerably increased corrosion circle; the center of the circle was black, indicating that the silver layer in the area had corroded. After 15 days of immersion (Figure 2C), the corrosion circle further developed into a large area, and the area inside the circle showed a green color, which indicated that the vast majority of copper corrosion products accumulated on the material surface. Most surface areas were yellowish brown, which means that the silver layer coating on the sample was incomplete.

The corrosion morphology of PCB-ImAg immersed in sterile and inoculated broths was further investigated by SEM (Figure 3). After immersion without bacteria for 3 and 6 days, the samples have relatively smooth and intact surfaces. Figure 3C shows that the surface was covered with some particles and became slightly rough after sample immersion in the sterile broth for 15 days. In the inoculated broth, the PCB-ImAg surface exhibited circular corrosion spots after 3 days of immersion (Figure 3D), which agreed with the optical images (Figure 2D). After the strains were cultured in the broth for 3 days, there was a certain concentration of metabolites in the broth, which accelerated microporous corrosion. Spores accumulated in the center of individual corrosion circles and nearby. During this period, the bacteria gathered into a cluster to adapt to the external environment. After immersion for 6 days (Figure 3E), a high concentration of cells had aggregated on the surface of the sample and formed a mature biofilm. The shape of the cells was rod-like, indicating that the cells were adapted to the test conditions and had developed from spores to vegetative cells. At same time, the bacteria in the biofilm possessed greater toxicity resistance (Gen et al., 2011). Therefore, the B. cereus cells began to rapidly propagate after the formation of the biofilm. Figure 3F shows the surface topography of a sample after being immersed in the inoculated broth for 15 days. The surface of the samples had severely deteriorated, and pits and peeling were observed. There was not only pitting on the surface but also large quantities of corrosion products that accumulated around the pits. A partial enlargement of area $\mathrm{C}$ shows spores and broken biofilm scattered on the surface of pits, which indicated that the cells had been attached here and formed a mature biofilm. After 15 days, there was a lack of nutrition, large amounts of toxic metabolites accumulated, and more copper and silver ions diffused in the broth, causing some cells to stop metabolizing and to form dormant spores. 


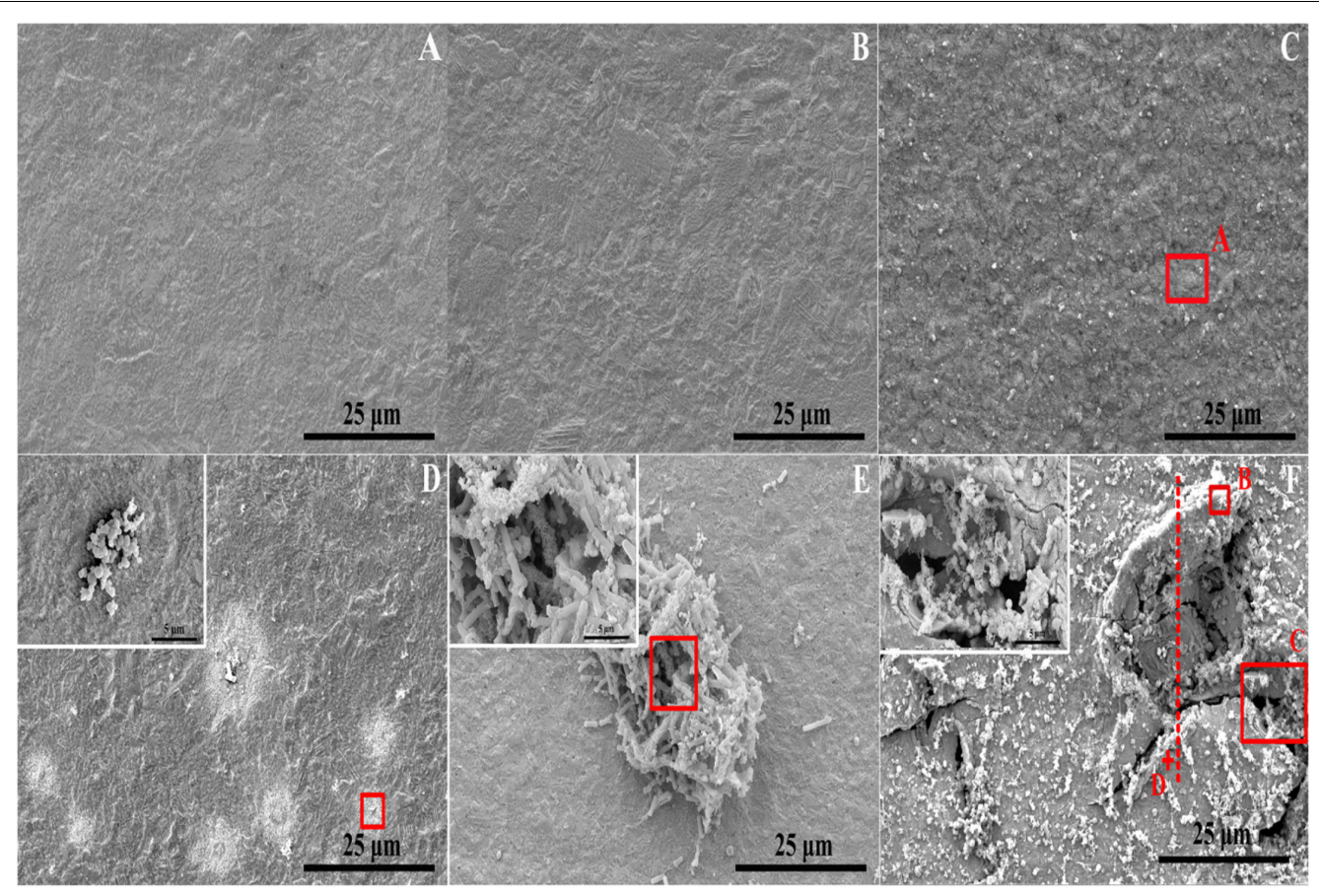

FIGURE 3 | Microstructure determined via FESEM on sample surface: (A-C) immersed in the broth without B. cereus for 3, 6, and 15 days and (D-F) immersed in the broth with $B$. cereus for 3,6 , and 15 days.
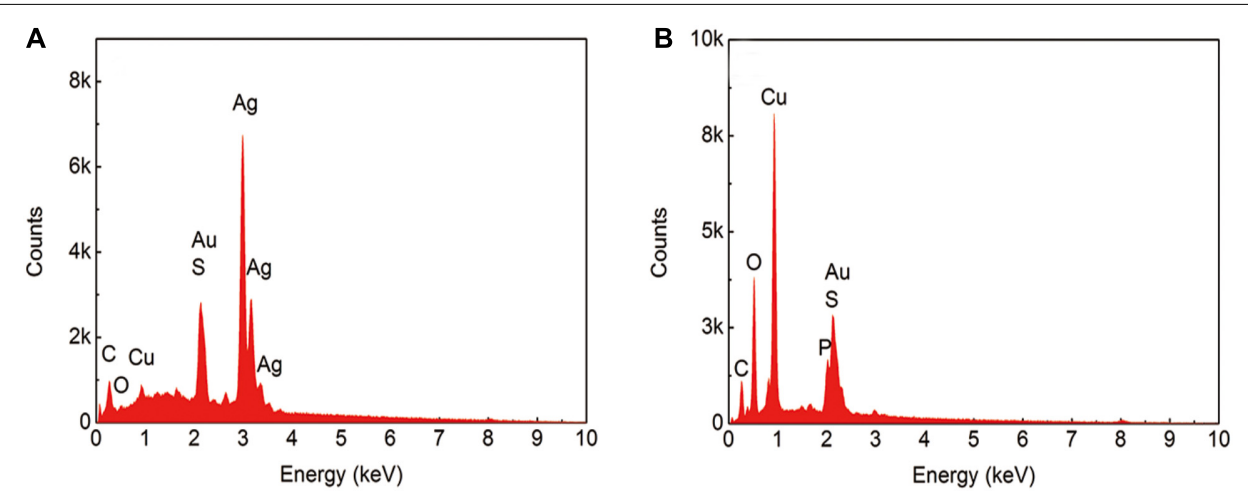

FIGURE 4 | EDS results from the sample after immersion in the broth without (A) and with (B) B. cereus for 15 days.

Figure 4 shows the scanning results for areas $\mathrm{A}$ and $\mathrm{B}$ in Figure 3. In the sterile broth (Figure 4A), the silver content at the sample surface was much higher than the copper content, indicating that the silver layer remained intact and that the base copper was well protected. Figure 4B shows the energy dispersive $\mathrm{X}$-ray spectroscopy (EDS) results for the corrosion pit on the sample immersed in the inoculated broth. The silver content in this area was much lower than the copper content, and the oxygen concentration was relatively high, indicating that the main component in the area may be copper oxide. The peak for phosphorous is also visible, which could be caused by the presence of the bacterial cells and their metabolites.

Figure 5 shows a cross-sectional view of the dotted line shown in Figure 3F. As indicated, the value of $\mathrm{Ag}: \mathrm{Cu}$ in area $\mathrm{D}$ was
16.64:26.21 according to the EDS result, which means that the silver layer partially remained on the sample surface. However, this view shows obvious pits and cracks under the surface, indicating a large loss of the base copper and silver, which led to the collapsed surface morphology. According to the results from elemental distribution mapping of the selected area, the $\mathrm{Ag}$ content was lower than the $\mathrm{Cu}$ content, indicating that the silver layer had almost completely dissolved in this area. The $\mathrm{O}$ content was slightly lower on the surface of defects than on the outside of pits (Figure 4B). Combined with the previous analysis, the adherence of the biofilm and elevated metabolism led to corrosion acceleration in areas where bacteria adhered.

Figure 6 shows the Ag 3d5/2 XPS spectra of the green area of PCB-ImAg immersed in broth with and without B. cereus 


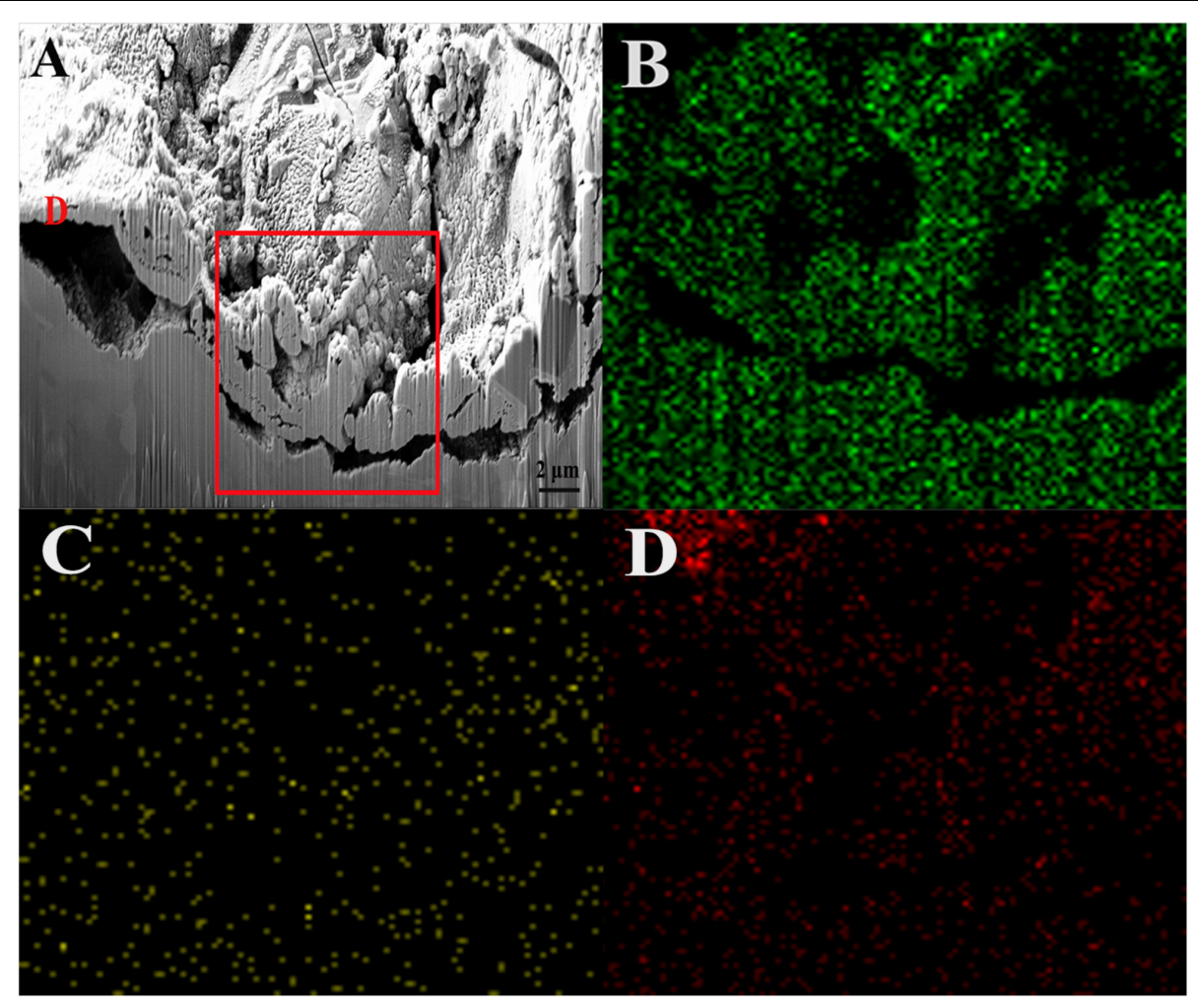

FIGURE 5 | FIB image and element mapping of the damaged area of the sample after immersion in the broth with B. cereus for 15 days: (A) FIB, (B) Cu, (C) Ag, and (D) $O$.
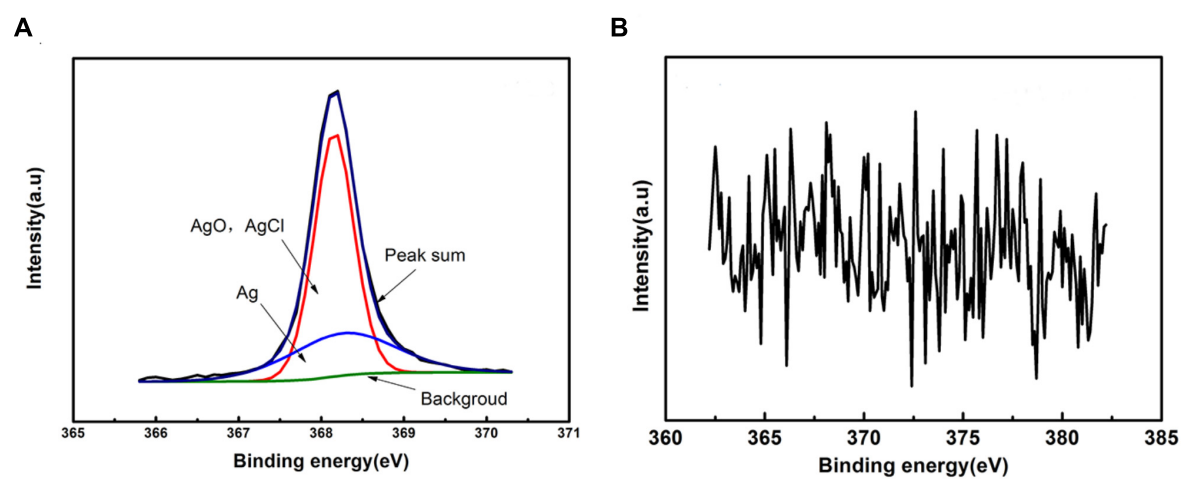

FIGURE 6 | XPS spectra of the sample after immersed in the broth without (A) and with (B) B. cereus for 15 days.

for 15 days. The maximum point on the peaks represents the content of the corrosion products. For the sterile broth, the Ag $3 \mathrm{~d}$ spectrum exhibits two peak components. Peak 1 appears at $368.16 \mathrm{eV}$ and consists of pure silver (Ag), AgCl, and AgO (Qian et al., 2019). Peak 2, located at $368.26 \mathrm{eV}$, may be attributed to pure silver (Ag) (Hammond et al., 1975). This peak disappeared after 15 days of immersion in the inoculated broth, indicating that the silver layer was severely damaged.

Figure 7 shows the Raman spectra obtained from the green area of samples after 15 days of immersion with and without $B$. cereus. The intensity of samples after immersion with $B$. cereus for 15 days was higher, indicating that there were more corrosion products in the presence of bacteria than in the control. In the lower wavenumber region, the samples exhibited the same main bands at $142,525,613$, and $1356 \mathrm{~cm}^{-1}$. The bands at 525 and $625 \mathrm{~cm}^{-1}$ indicated the existence of $\mathrm{Cu}_{2} \mathrm{O}$ (Kosec et al., 2015). The bands at $142 \mathrm{~cm}^{-1}$ were assigned to the $\mathrm{OCuO}$ bending mode (Frost, 2003). The presence of $\mathrm{CuO}$ was validated by the broad doublet from 525 to $635 \mathrm{~cm}^{-1}$ (Chan et al., 1999; Xu et al., 1999). The band at $1356 \mathrm{~cm}^{-1}$ indicated the presence of $\mathrm{Cu}_{2} \mathrm{Cl}(\mathrm{OH})_{3}$ and $\mathrm{CuCl}_{2} \cdot 2 \mathrm{H}_{2} \mathrm{O}$ (Frost, 2003). However, the band at $217 \mathrm{~cm}^{-1}$ was only observed in the control samples and was probably from 

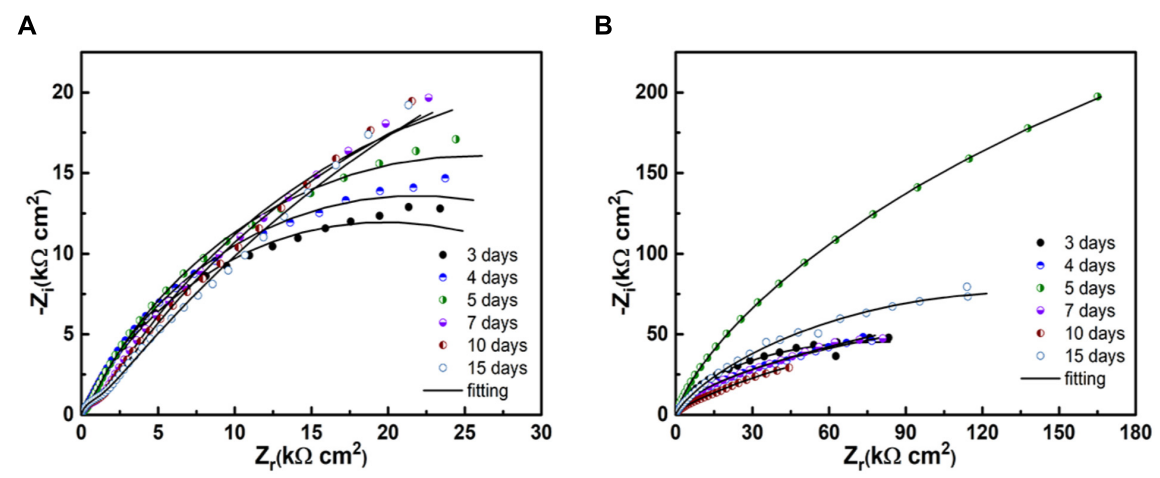

FIGURE 7 | EIS of the samples after immersion in the broth without (A) and with (B) the B. cereus.

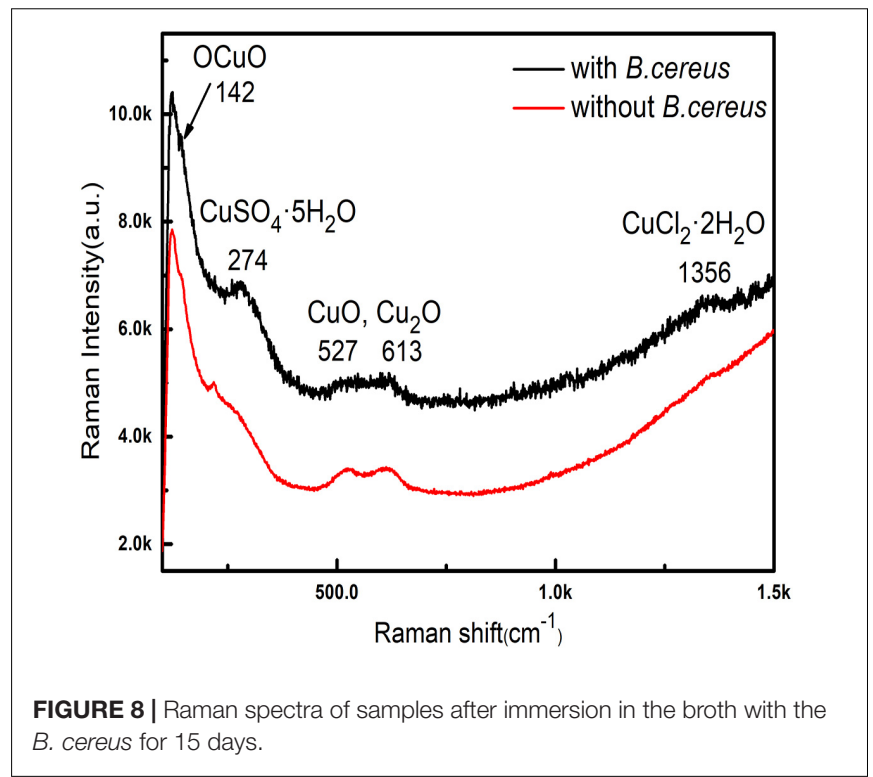

$\mathrm{Cu}_{2} \mathrm{O}$ (Kosec et al., 2015). The band at $274 \mathrm{~cm}^{-1}$ was observed only in the samples after immersion with $B$. cereus. According to a previous study (Berger, 1976), this band could be assigned to copper sulfate pentahydrate $\left(\mathrm{CuSO}_{4} \cdot 5 \mathrm{H}_{2} \mathrm{O}\right)$, which is formed by sulfur-containing metabolites. The Raman spectra indicated that the main corrosion products from the samples after immersion were $\mathrm{Cu}_{2} \mathrm{O}$ and $\mathrm{CuO}$. However, owing to the effects of $B$. cereus, the products of the sample immersed in the broth with $B$. cereus also contained $\mathrm{CuSO}_{4} \cdot 5 \mathrm{H}_{2} \mathrm{O}$.

Figure 8 shows the Nyquist diagrams of PCB-ImAg immersed in broth with and without $B$. cereus for different times. In both cases, the spectra have two time constants. In the presence of $B$. cereus, the size of the capacitance arc increased in the first 5 days of immersion and decreased after 7 days. The result of samples immersed with $B$. cereus showed that as the test time progressed, the formation of the biofilm and corrosion products followed a dynamic process.

Figure 9 shows the model used for the spectra after immersion with and without cells considering any defects on the surface.

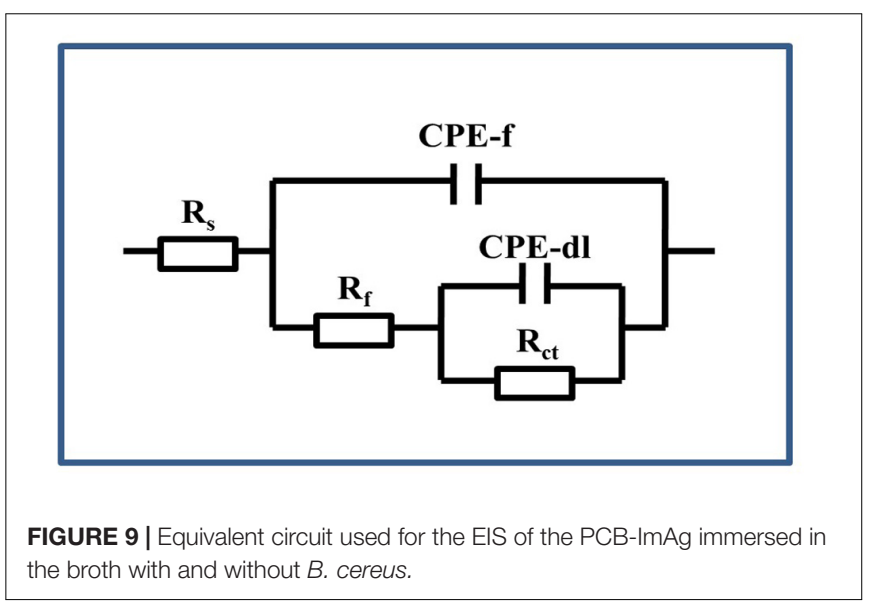

The related parameters are presented in Table 1 . The variable $R_{s}$ is the solution resistance; $R_{f}$ is the resistance of the film; $R_{c t}$ is the charge transfer resistance, representing the reaction rate of the base; and CPE-f and CPE-dl are parameters for the film and the double layer of the film electrolyte interface, respectively. A constant phase element (CPE) is often used instead of a capacitance to account for the non-ideal capacitance response due to the almost complete absence of pure capacitance in actual electrochemical processes (Mansfeld et al., 1993). Table 1 lists the corresponding parameters for both cases; the values for $R_{s}$ are low because all of the broths used in the tests contained $\mathrm{NaCl}$. For the sterile broth, the values of $R_{c t}$ continued to increase during the test. Because microporous corrosion occurred slowly, corrosion products migrated through and blocked the micropores (Qian et al., 2018). For 15 days, some corrosion products covered the surfaces of the samples and accumulated on the surface, so that the film prevented the reaction of the base copper. $R_{f}$ and $R_{c t}$ for the samples immersed in $B$. cereus broth were much higher than those of the control sample, and the values first increased and then decreased. The variable $R_{f}$ describes the film formation on the surface of the sample. This film formation process is complex, comprising the dynamic generation of biofilms and formation of corrosion products (Xu et al., 2018). Combined with the surface analysis shown in Figures 2-5, we can infer that on the third 
TABLE 1 | Fitting parameters of EIS of PCB-ImAg after immersed in the broth.

\begin{tabular}{|c|c|c|c|c|c|}
\hline T/days & $\begin{array}{c}R_{s} \\
\left(\Omega \mathrm{cm}^{2}\right)\end{array}$ & $\begin{array}{c}\text { CPE-f } \\
\left(\mu \mathrm{F} \mathrm{cm}^{-2}\right)\end{array}$ & $\begin{array}{c}R_{f} \\
\left(\mathrm{k} \Omega \mathrm{cm}^{2}\right)\end{array}$ & $\begin{array}{c}\text { CPE-dl } \\
\left(\mu \mathrm{F} \mathrm{cm}^{-2}\right)\end{array}$ & $\begin{array}{c}R_{c t} \\
\left(\mathbf{k} \Omega \mathrm{cm}^{2}\right)\end{array}$ \\
\hline \multicolumn{6}{|c|}{ Without $B$. cereus } \\
\hline 3 & 8.2 & 27.0 & 0.3 & 94.0 & 39.8 \\
\hline 4 & 7.8 & 22.9 & 0.3 & 109.0 & 43.6 \\
\hline 5 & 7.6 & 19.5 & 0.4 & 123.2 & 50.9 \\
\hline 7 & 7.0 & 16.6 & 1.2 & 145.6 & 70.2 \\
\hline 10 & 7.1 & 16.1 & 1.3 & 148.0 & 81.9 \\
\hline 15 & 7.1 & 15.3 & 1.3 & 140.1 & 119.1 \\
\hline \multicolumn{6}{|c|}{ With B. cereus } \\
\hline 3 & 10.2 & 26.2 & 2.5 & 15.8 & 207.6 \\
\hline 4 & 9.1 & 14.5 & 4.6 & 24.1 & 369.5 \\
\hline 5 & 9.2 & 22.1 & 46.8 & 8.4 & 1163.0 \\
\hline 7 & 8.2 & 14.9 & 6.0 & 26.9 & 446.6 \\
\hline 10 & 8.6 & 20.2 & 4.6 & 59.7 & 217.9 \\
\hline 15 & 9.5 & 12.6 & 6.9 & 17.3 & 294.2 \\
\hline
\end{tabular}

day, the $B$. cereus accumulated on the surface increased the value of $R_{f}$. After 5 days, the bacteria had grown to form a mature biofilm adhering to the surface and preventing corrosion of the base copper. As the biofilm on the surface aged and broke, $R_{c t}$ and $R_{f}$ decreased sharply. On the fifteenth day, there were obvious defects on the sample surface. The FIB image shows that the base copper at the silver rupture was directly exposed to the solution, which increased the corrosion rate of the base copper, and corrosion products accumulated on the surface preventing reaction of the base material.

\section{DISCUSSION}

The growth test showed that the strains used in the test have a certain tolerance to silver and copper ions. The bacteria could grow and reproduce in broth containing $25 \mathrm{mg} / \mathrm{L}_{\mathrm{AgNO}_{3}}$, and $\mathrm{CuSO}_{4}$ concentrations below $200 \mathrm{mg} / \mathrm{L}$ did not obviously affect cell growth in the growth test. This growth characteristic greatly assisted the bacteria to adhere and grow on the surface of PCBImAg. It is known that silver ions have strong antibacterial properties (Teitzel and Parsek, 2003). The trace element copper is an essential nutrient in a certain concentration (Santo et al., 2011); however, when that concentration is exceeded, the ions reduce the microbial activity and number. Letelier et al. (2010) reported that the non-specific protein-binding properties of copper ions can increase their pro-oxidant activity when damaging biomolecules. However, a low concentration of copper ions can also increase enzyme activity and protein synthesis, causing cells to have more tightly packed arrays intrinsic to plasma membranes (Prior and Dalton, 1985). Therefore, there is a difference in the tolerance of the bacteria to the two ions. Furthermore, the complexation of metal ions by the organics in solution (Thurman et al., 1989) and the biosorption of heavy metal ions onto $B$. cereus biomass has previously been reported (Hasan et al., 2016); these effects reduced toxicity due to a decrease in the effective ion concentration in the solution. For example, we have found that when $400 \mathrm{mg} / \mathrm{L}$
$\mathrm{CuSO}_{4}$ was added, the concentration of copper ion in LB broth was only $150 \mathrm{mg} / \mathrm{L}$ by ICP. Despite this significant reduction in free copper ions, the $B$. cereus used in this experiment has relatively high copper tolerance compared with the strains reported in other studies. According to Sokhn et al. (2001) and Teitzel and Parsek (2003), 770 ppm copper ions could significantly reduce microbial activity of soil bacteria, and the growth of Pseudomonas aeruginosa was completely inhibited in the broth with 128 ppm copper ions. In an earlier work, Singh et al. (1985) also reported a 98\% decrease in the cell viability of Yersinia enterocolitica after 2 days in the presence of $1 \mathrm{mg} / \mathrm{L}$ copper.

Surface analysis of the samples indicated that the corrosion behavior of PCB-ImAg with B. cereus is related to the biofilm formation and metabolism. According to a previous study (Zou et al., 2013), PCB-ImAg has good protection against $\mathrm{Cl}^{-}$; thus, in the sterile broth, only slight corrosion occurred on the surface of the material after immersion for 15 days, and the silver layer was intact, protecting the base copper. The silver layer was very thin, and there were defects, such as micropores, on the surface of the sample. Therefore, the copper base was exposed to the broth, which led to microporous corrosion. As shown in Figure 3D, the areas of microporous corrosion were weak points that had more copper corrosion products, a thinner silver layer, and less toxicity and favored further growth of the strain. When the strains formed mature biofilms, the large amount of oxygen consumed by cellular respiration led to different oxygen concentrations inside and outside of the biofilm, causing oxygen concentration corrosion. Additionally, the large amount of metabolites accelerated microporous corrosion and creep corrosion. This result was confirmed by the differences in $\mathrm{O}$ content in distinct areas, as shown in the EDS results.

The results of XPS and Raman analyses show different compositions of the compounds in both cases. In the bacterial broth, the corrosion products contained copper oxides and chlorides; $\mathrm{CuSO}_{4} \cdot 5 \mathrm{H}_{2} \mathrm{O}$ was present on the surface of the sample. In addition, elemental Ag was not clearly apparent in the peaks (Figure 6B), indicating that the silver layer in the area had been damaged.

Biofilm formation and metabolic activity are closely related according to EIS results. In the sterile broth, as the immersion time increased, the corrosion process of samples was slow and a dense silver layer protected the base copper by hindering further corrosion of the base. Moreover, corrosion products that blocked micropores on the surface could also retard copper base reaction. The changes in the EIS results for the bacterial broth were caused by interactions between the PCB-ImAg and bacterial metabolism. At the beginning of the test, microporous corrosion was accelerated by bacteria, and corrosion products contained dense $\mathrm{Cu}_{2} \mathrm{O}$ (Figure 7; Strandberg, 1998), which caused the values of $\mathrm{R}_{c t}$ to be higher than that of control at the same time. With the adsorption of the mature biofilm, corresponding sharp increases were observed in $\mathrm{R}_{f}$ and $\mathrm{R}_{c t}$. In addition, high concentration of metabolites under the biofilm continued to corrode the copper base (Xu et al., 2017). After the biofilm broke down, the copper base exposure to the broth aggravated galvanic corrosion and caused further consumption of the copper base. 
Moreover, the thick film of copper corrosion products covered on the surface increased $\mathrm{R}_{c t}$ slightly.

PCB-ImAg is usually used in atmospheric environment, the composition of which is quite complex and variable and may include $\mathrm{H}_{2} \mathrm{~S}, \mathrm{SO}_{2}, \mathrm{HCl}$, particulates, etc. To study atmospheric corrosion, simplified solutions were typically used simulating only the ionic compositions and concentrations. These solutions, however, are not suitable to study the MIC of PCB due to the lack of sufficient organic nutrients to support the bacterial growth. Under such considerations, LB broth was used as test medium in this study to allow bacteria to grow and reproduce, so the corrosion acceleration of the PCB-ImAg also be amplified and the authors could observe the interaction between the materials and the bacteria could be more clearly investigated. The results of the sterile control indicated the organic ingredients in LB broth did not present significant corrosiveness to the PCB as only slight corrosion had occurred on the PCB surface. Therefore, the rapid deterioration of the PCB surface in $B$. cereus inoculated medium was closely related to the life activities of the bacteria.

Nevertheless, a noteworthy limitation in this study was the use of much more concentrated organic nutrients than the actual atmospheric environment may contain. In this sense, future works will explore the uses of culture media that can more closely simulate the atmospheric environments. For example, a more realistic culture medium could be obtained by analyzing the composition of the thin electrolyte film formed bacteriagrown specimens exposed under real atmosphere. The simulated solution may also be supplemented with varied concentration of organic nutrients to further understand their roles in the MIC of PCBs. Interestingly, previous studies (Qian et al., 2018; Gu et al., 2019) have found that microbes starved with organic nutrients may more aggressively corrode metals via extracellular electron transfer using metals as electron donors.

\section{CONCLUSION}

The results from all the tests showed that the PCB-ImAg samples were unable to resist attacks from $B$. cereus in an aerobic medium. The following conclusions can be drawn from the results:

\section{REFERENCES}

Berger, J. (1976). Infrared and Raman spectra of CuSO4, 5H2O; CuSO4, 5D2O; and CuSeO4, 5H2O. J. Raman Spectrosc. 5, 103-114. doi: 10.1002 /jrs. 1250050202 doi: $10.1002 /$ jrs. 1250050202

Chan, H. Y. H., Takoudis, C. G., and Weaver, M. J. (1999). Oxide film formation and oxygen adsorption on copper in aqueous media as probed by surfaceenhanced Raman spectroscopy. J. Phys. Chem. B. 103, 357-365. doi: 10.1021/ jp983787c

Flemming, H. C. (1996). "Biofuling and microbilogically influenced corrosion (MIC): an economical and technical overview," in Microbial Deterioration Materiaols, eds E. Heitz, H.-C. Flemming, and W. Sand (Heidelberg: Springer), 5-14. doi: 10.1007/978-3-642-800 17-7_2

Frost, R. L. (2003). Raman spectroscopy of selected copper minerals of significance in corrosion. Spectrochim. Acta Part A 59, 1195-1204. doi: 10.1016/s13861425(02)00315-3
(1) B. cereus has a high copper tolerance and a certain silver tolerance, as $400 \mathrm{mg} / \mathrm{L}$ of copper sulfate cannot completely inhibit its growth.

(2) In the LB broth, MIC caused by $B$. cereus was the result of several factors. The biofilm of $B$. cereus promotes microporous corrosion possibly by producing metabolites. Simultaneously, the biofilm that adhered to the surface probably led to an oxygen concentration cell, and metabolites accelerated the microporous corrosion.

(3) The EIS data show that B. cereus promotes corrosion of the base copper, leading to a very thick layer of corrosion products accumulating on the surface. This result was demonstrated in the spectra, in which all the $R_{f}$ and $R_{c t}$ values were higher than those in the sterile broth.

\section{DATA AVAILABILITY}

The datasets generated for this study are available on request to the corresponding author.

\section{AUTHOR CONTRIBUTIONS}

$\mathrm{YH}$ and $\mathrm{KX}$ designed the experiments. $\mathrm{YH}$ carried out the experiments, analyzed the data, and drafted the manuscript. PY and RX assisted in carrying out some experiments. DZ, CD, and $\mathrm{XL}$ revised the manuscript. All authors read and approved the final manuscript.

\section{FUNDING}

This work was supported by the National Natural Science Foundation of China (Nos. 51671027, 51271032, and 51131005), the National Basic Research Program of China (973 Program, No. 2014CB643300), and the National Environmental Corrosion Platform (NECP).

Gen, W., Chen, X., Hu, A., and Li, M. (2011). Effect of Ag on oxidation of Cubase leadframe. Microelectron. Reliab. 1, 866-870. doi: 10.1016/j.microrel.2010. 10.010

Gu, T., Jia, R., Unsal, T., and Xu, D. (2019). Toward a better understanding of microbiologically influenced corrosion caused by sulfate reducing bacteria. J. Mater. Sci. Technol. 35, 631-636. doi: 10.1016/j.jmst.2018.10.026

Hammond, J. S., Gaarenstroom, S. W., and Winograd, N. (1975). X-ray photoelectron spectroscopic studies of cadmium-and silver-oxygen surfaces. Anal. Chem. 47, 2193-2199. doi: 10.1021/ac60363a019

Hasan, H. A., Abdullah, S. R. S., Kofli, N. T., and Yeoh, S. J. (2016). Interaction of environmental factors on simultaneous biosorption of lead and manganese ions by locally isolated Bacillus cereus. J. Ind. Eng. Chem. 37, 295-305. doi: 10.1016/j.jiec.2016.03.038

Hou, B., Li, X., Ma, X., Du, C., Zhang, D., Zheng, M., et al. (2017). The cost of corrosion in China. npj Mater. Degrad. 1:4.

Huang, H., Dong, Z., Chen, Z., and Guo, X. (2011). The effects of Cl- ion concentration and relative humidity on atmospheric corrosion behaviour of 
PCB-Cu under adsorbed thin electrolyte layer. Corros. Sci. 53, 1230-1236. doi: 10.1016/j.corsci.2010.12.018

Huang, L., Li, Z., Lou, Y., Cao, F., Zhang, D., and Li, X. (2018). Recent advances in scanning electrochemical microscopy for biological applications. Materials 11:1389. doi: 10.3390/ma11081389

Jia, R., Unsal, T., Xu, D., Lekbach, Y., and Gu, T. (2019). Microbiologically influenced corrosion and current mitigation strategies: a state of the art review. Int. Biodeterior. Biodegrad. 137, 42-58. doi: 10.1016/j.ibiod.2018.11.007

Juzeliūnas, E., Ramanauskas, R., Lugauskas, A., Samulevičienè, M., and Leinartas, K. (2005). Microbially influenced corrosion acceleration and inhibition. EIS study of $\mathrm{Zn}$ and $\mathrm{Al}$ subjected for two years to influence of Penicillium frequentans, Aspergillus niger and Bacillus mycoides. Electrochem. Commun. 7, 305-311. doi: 10.1016/j.elecom.2005.01.012

Kosec, T., Qin, Z., Chen, J., Legat, A., and Shoesmith, D. W. (2015). Copper corrosion in bentonite/saline groundwater solution: effects of solution and bentonite chemistry. Corros. Sci. 90, 248-258. doi: 10.1016/j.corsci.2014.10.017

Letelier, M. E., Sánchez-Jofré, S., Peredo-Silva, L., Cortés-Troncoso, J., and Aracena-Parks, P. (2010). Mechanisms underlying iron and copper ions toxicity in biological systems: pro-oxidant activity and protein-binding effects. Chem. Biol. Interact. 188, 220-227. doi: 10.1016/j.cbi.2010.06.013

Li, Y., Xu, D., Chen, C., Li, X., Jia, R., Zhang, D., et al. (2018). Anaerobic microbiologically influenced corrosion mechanisms interpreted using bioenergetics and bioelectrochemistry: a review. J. Mater. Sci. Technol. 34, 1713-1718. doi: 10.1016/j.jmst.2018.02.023

Mansfeld, F., Wang, Y., Lin, S. H., Xiao, H., and Shih, H. (1993). "Detection and monitoring of localized corrosion by EIS," in Electrochemical Impedance: Analysis and Interpretation., eds J. Scully, D. Silverman, and M. Kendig West Conshohocken, PA: ASTM International. 297-312. doi: 10.1520/stp18076s

Nakamura, K., and Silver, S. (1994). Molecular analysis of mercury-resistant Bacillus isolates from sediment of Minamata Bay, Japan. Appl. Environ. Microbiol. 60, 4596-4599.

Nourbakhsh, M. N., Kiliçarslan, S., Ilhan, S., and Ozdag, H. (2002). Biosorption of $\mathrm{Cr} 6+, \mathrm{Pb} 2+$ and $\mathrm{Cu} 2+$ ions in industrial waste water on Bacillus sp. Chem. Eng. J. 85, 351-355. doi: 10.1016/s1385-8947(01)00227-3

Novikova, N., De Boever, P., Poddubko, S., Deshevaya, E., Polikarpov, N., and Rakova, N. (2006). Survey of environmental biocontamination on board the International Space Station. Res. Microbiol. 157, 5-12. doi: 10.1016/j.resmic. 2005.07.010

Prior, S. D., and Dalton, H. (1985). The effect of copper ions on membrane content and methane monooxygenase activity in methanol-grown cells of Methylococcus capsulatus (Bath). Microbiology 131, 155-163. doi: 10.1099/ 00221287-131-1-155

Qian, H., Yang, J., Lou, Y., ur Rahman, O., Li, Z., and Ding, X. (2019). Musselinspired superhydrophilic surface with enhanced antimicrobial properties under immersed and atmospheric conditions. Appl. Surf. Sci. 465, 267-278. doi: 10.1016/j.apsusc.2018.09.173

Qian, H., Zhang, D., Lou, Y., Li, Z., Xu, D., Du, C., et al. (2018). Laboratory investigation of microbiologically influenced corrosion of Q235 carbon steel by halophilic archaea Natronorubrum tibetense. Corros. Sci. 145, 151-161. doi: 10.1016/j.corsci.2018.09.020

Qu, Q., He, Y., Wang, L., Xu, H., Li, L., and Chen, Y. (2015). Corrosion behavior of cold rolled steel in artificial seawater in the presence of Bacillus subtilis C2. Corros. Sci. 91, 321-329. doi: 10.1016/j.corsci.2014.11.032

Russo, S. G., Henderson, M. J., and Hinton, B. R. W. (2002). Corrosion of an aircraft radar antenna waveguide. Eng. Fail. Anal. 9, 423-434. doi: 10.1016/ S1350-6307(01)00028-0

Santo, C. E., Lam, E. W., Elowsky, C. G., Quaranta, D., Domaille, D. W., Chang, C. J., et al. (2011). Bacterial killing by dry metallic copper surfaces. Appl. Environ. Microbiol. 77, 794-802. doi: 10.1128/aem.01599-10

Shivaji, S., Chaturvedi, P., Suresh, K., Reddy, G. S. N., Dutt, C. B. S., and Wainwright, M. (2006). Bacillus aerius sp. nov., Bacillus aerophilus sp. nov., Bacillus stratosphericus sp. nov. and Bacillus altitudinis sp. nov., isolated from cryogenic tubes used for collecting air samples from high altitudes. Int. J. Syst. Evol. Microbiol. 56, 1465-1473. doi: 10.1099/ijs.0.64029-0

Siddiqui, S., Siddiqui, Z. A., and Ahmad, I. (2005). Evaluation of fluorescent Pseudomonads and Bacillus, isolates for the biocontrol of a wilt disease complex of pigeonpea. World J. Microbiol. Biotechnol. 21, 729-732. doi: 10.1007/s11274004-4799-z
Singh, A., LeChevallier, M. W., and McFeters, G. A. (1985). Reduced virulence of Yersinia enterocolitica by copper-induced injury. Appl. Environ. Microbiol. 50, 406-411.

Sokhn, J., De Leij, F. A. A. M., Hart, T. D., and Lynch, J. M. (2001). Effect of copper on the degradation of phenanthrene by soil micro-organisms. Lett. Appl. Microbiol. 33, 164-168. doi: 10.1046/j.1472-765x.2001.00972.x

Strandberg, H. (1998). Reactions of copper patina compounds-II. Influence of sodium chloride in the presence of some air pollutants. Atmos. Environ. 32, 3521-3526. doi: 10.1016/S1352-2310(98)00058-2

Teitzel, G. M., and Parsek, M. R. (2003). Heavy metal resistance of biofilm and planktonic Pseudomonas aeruginosa. Appl. Environ. Microbiol. 69, 2313-2320. doi: 10.1128/aem.69.4.2313-2320.2003

Thurman, R. B., Gerba, C. P., and Bitton, G. (1989). The molecular mechanisms of copper and silver ion disinfection of bacteria and viruses. Crit. Rev. Environ. Sci. Technol. 18, 295-315. doi: 10.1080/10643388909388351

Xiao, K., Yi, P., Yan, L., Bai, Z., Dong, C., and Dong, P. (2017). Corrosion behavior of silver-plated circuit boards in a simulated marine environment with industrial pollution. Materials 10: 762. doi: 10.3390/ma10070762

$\mathrm{Xu}, \mathrm{D}$., and $\mathrm{Gu}, \mathrm{T}$. (2014). Carbon source starvation triggered more aggressive corrosion against carbon steel by the Desulfovibrio vulgaris biofilm. Int. Biodeterior. Biodegrad. 91, 74-81. doi: 10.1016/j.ibiod.2014.03.014

$\mathrm{Xu}, \mathrm{D} ., \mathrm{Li}, \mathrm{Y}$., and Gu, T. (2016). Mechanistic modeling of biocorrosion caused by biofilms of sulfate reducing bacteria and acid producing bacteria. Bioelectrochemistry 110, 52-58. doi: 10.1016/j.bioelechem.2016.03.003

Xu, D., Li, Y., Song, F., and Gu, T. (2013). Laboratory investigation of microbiologically influenced corrosion of $\mathrm{C} 1018$ carbon steel by nitrate reducing bacterium Bacillus licheniformis. Corros. Sci. 77, 385-390. doi: 10.1016/j.corsci. 2013.07.044

Xu, D., Xia, J., Zhou, E., Zhang, D., Li, H., Yang, C., et al. (2017). Accelerated corrosion of 2205 duplex stainless steel caused by marine aerobic Pseudomonas aeruginosa biofilm. Bioelectrochemistry 113, 1-8. doi: 10.1016/j.bioelechem. 2016.08.001

Xu, D., Zhou, E., Zhao, Y., Li, H., Liu, Z., Zhang, D., et al. (2018). Enhanced resistance of $2205 \mathrm{Cu}$-bearing duplex stainless steel towards microbiologically influenced corrosion by marine aerobic Pseudomonas aeruginosa biofilms. J. Mater. Sci. Technol. 34, 1325-1336. doi: 10.1016/j.jmst.2017.11.025

Xu, J. F., Ji, W., Shen, Z. X., Li, W. S., Tang, S. H., Ye, X. R., et al. (1999). Raman spectra of CuO nanocrystals. J. Raman Spectrosc. 30, 413-415. doi: 10.1002/ (SICI)1097-4555(199905)30:5<413::AID-JRS387<3.0.CO;2-N

Yan, L., Xiao, K., Yi, P., Dong, C., Wu, J., Bai, Z., et al. (2017). The corrosion behavior of PCB-ImAg in industry polluted marine atmosphere environment. Mater. Des. 115, 404-414. doi: 10.1016/j.matdes.2016.11.074

Yan, L., Xiao, K., Yi, P., Dong, C., Wu, J., Mao, C., et al. (2016). Surface analysis of silver-plated circuit boards in a salt-spray environment. J. Alloys Compd. 688, 301-312. doi: 10.1016/j.jallcom.2016.07.207

Yi, P., Xiao, K., Ding, K., Yan, L., Dong, C., and Li, X. (2016). Initial corrosion behavior of a copper-clad plate in typical outdoor atmospheric environments. Electron. Mater. Lett. 12, 163-170. doi: 10.1007/s13391-015-5309-1

Yousaf, M., Ali, I., Arif, M. A., Mustafa, G. M., Ahmad, S., and Afzal, N. (2015). Effects of microbiologically influenced corrosion by Bacillus megaterium bacteria on the mechanical properties of Al-Cu Alloy. Mater. Today Proc. 2, 5669-5673. doi: 10.1016/j.matpr.2015.11.107

Zou, S., Li, X., Dong, C., Ding, K., and Xiao, K. (2013). Electrochemical migration, whisker formation, and corrosion behavior of printed circuit board under wet H2S environment. Electrochim. Acta 114, 363-371. doi: 10.1016/j.electacta. 2013.10.051

Conflict of Interest Statement: The authors declare that the research was conducted in the absence of any commercial or financial relationships that could be construed as a potential conflict of interest.

Copyright (C) $2019 \mathrm{Hu}$, Xiao, Zhang, Yi, Xiong, Dong, Wu and Li. This is an openaccess article distributed under the terms of the Creative Commons Attribution License (CC BY). The use, distribution or reproduction in other forums is permitted, provided the original author(s) and the copyright owner(s) are credited and that the original publication in this journal is cited, in accordance with accepted academic practice. No use, distribution or reproduction is permitted which does not comply with these terms. 